\title{
¿Universidades Públicas?: Financiamiento Fiscal para o contra la Equidad de Oportunidades.
}

\author{
Dr. Augusto Samaniego M \\ Profesor Departamento Historia y Presidente Asociación Académicos, \\ Universidad de Santiago de Chile (USACH)
}

La alianza estratégica entre la Universidad de Chile (UCH) y la Pontificia Universidad Católica de Chile (PUC), anunciada recientemente, nos señala la urgencia de asumir posturas que contribuyan a esclarecer un concepto de Universidad Pública necesario y posible en la realidad nacional contemporánea.

Dicha urgencia tiene que ver con el grado de involucración del gobierno en el argumento de que sólo un par de universidades serían lo suficientemente complejas como para recibir recursos frescos destinados a elevar la investigación científicotecnológica y los post-grados que la amplifiquen. Pareciera, así, que la crisis de la educación compromete la idea misma de universidad. ¿Podemos conformarnos, o simplemente adecuarnos, a argumentos que postulan universidades (exclusivamente) docentes?. ¿La universidad republicana que heredamos desde 1843, puede existir sin la interacción de la creación de conocimientos, la formación y la comunicación extensiva?.

La inversión en educación superior, que alcanzó aproximadamente el 1,3\% del Producto Interno Bruto (P.I.B). nacional en 1973, bordea aún el 0,6\%. Es de gran relevancia, por cierto, incrementar la inversión en investigación; pero ese ámbito debiera tratarse teniendo en cuenta que el aporte imprescindible de la universidad a la Nación será el resultado de un conjunto articulado de tareas. Siempre, la misión y los roles de las universidades públicas requerirán crear conocimientos y formar con ellos. Pero, además, realizar su quehacer complejo conforme a objetivos de desarrollo social democrático. Entendemos que es ése el fundamento del único enunciado sobre políticas públicas respecto a la educación superior, claramente reiterado por los gobiernos post-dictadura: Crecimiento de la calidad y de la equidad de oportunidades.

Identifiquemos, sucintamente, algunos hechos que nos permitan razonar acerca de la evidente existencia de una pirámide educacional (desde la básica a la superior) profundamente segmentada. Es decir, en la cual opera la discriminación en virtud de los recursos económicos de los estudiantes que van accediendo a niveles superiores de la educación.

Las dos universidades que firmaron la alianza estratégica citada han percibido los mayores aportes estatales a sus presupuestos (AFD, AFI y otros). De tal modo, el financiamiento fiscal que reciben anualmente por alumno, duplica o más que triplica lo recibido por otras universidades, particularmente las quince estatales restantes. Esa forma de distribuir la inversión estatal resulta en una real política pública que aumenta la inequidad de oportunidades, puesto que las dos universidades más beneficiadas nos muestran la siguiente característica respecto del origen socio-económico de los jóvenes que ingresan a sus aulas:

Un $20 \%$ y un $50 \%$ de quienes ingresan a la PUC y UCH, respectivamente, provienen de la enseñanza media subvencionada o municipalizada. El 80 y $50 \%$ de quienes se 
forman en ambas universidades corresponde a estratos sociales con ingresos suficientes para usar de la educación media pagada. La gran pirámide educacional, constituida por estratos segregados culmina excluyendo del saber y la formación en esas casas de estudio a la gran mayoría de los jóvenes con talento. Los privilegios económico-sociales determinan a esas élites del poder del conocimiento del futuro.

En contraste con lo anterior las universidades del Estado a lo largo del territorio concentran el $45 \%$ de la matrícula universitaria. Quince de ellas (exceptuando la UCH) ingresan a sus aulas cerca de un $80 \%$ de alumnos que han cursado la enseñanza media municipalizada o subvencionada. Como el resto de las entidades que integran el Consejo de Rectores, ellas reciben aportes fiscales que, en promedio, son inferiores al $25 \%$ de sus presupuestos.

Un reciente estudio relativo a los amarres e inequidades del financiamiento fiscal a las universidades, tanto estatales como tradicionales privadas ${ }^{1}$ revela que no existe un padrón que regule la forma como se distribuyen los aportes del Estado (salvo el criterio de mantener los porcentajes históricos, es decir, definidos bajo la dictadura, para entregar el AFD).

Excluyendo los aportes extraordinarios a la Universidad de Chile (cerca de 6.000 millones de pesos anuales), las cifras de 1999 mostraron que, en su evolución, dichos aportes permanecen inferiores al P.I.B.

Al elaborar un índice de equidad básica como el resultado del cuociente de la matrícula total correspondiente a los sub-conjuntos (a) universidades estatales y (b) tradicionales privadas, llegamos a la siguiente conclusión: las universidades estatales han tenido un aumento proporcional mayor de las matrículas y las universidades tradicionales privadas han recibido más aporte fiscal, durante toda la década de los 90.

La conclusión gravísima es que la división de los aportes estatales por el número de matrículas en cada sub-conjunto y, luego, la división de esos dos valores, evidencia que los gobiernos entregaron a las universidades estatales:

- $\quad$ en 1990, el $90,73 \%$; y

- en 1998, el $91,95 \%$ de lo que entregaron a la universidades tradicionales privadas por alumno.

Este enfoque comparativo global no expresa la realidad de cada universidad. En ese sentido, apuntaremos ciertas conclusiones comparativas más específicas.

- La Universidad de Santiago de Chile (USACH, estatal), con matrícula superior a la de la Pontificia Universidad Católica (PUC, privada), ha recibido todos los años aportes claramente inferiores.

- La Universidad de Chile (estatal), con una matrícula similar a la de la USACH, ha recibido un aporte por alumno que más que duplica lo obtenido por esta última.

\footnotetext{
${ }^{1}$ Dr. Rafael Labarca B., Amarres e inequidades. El financiamiento fiscal de las universidades, en Augusto Samaniego (Coordinador), Las universidades públicas, ¿equidad en la educación superior chilena?, Stgo., LOM ediciones, enero 2001: pp. 63-73
} 
- El aporte de la Universidad de Concepción ha sido mayor (salvo en 1994) al recibido por la USACH.

- El aporte a la Universidad de Chile ha sido superior al entregado a la Pontificia Universidad Católica (PUC).

- Otros casos:

- La Universidad de Bío Bío (estatal) ha recibido el 70\% del aporte por alumno otorgado a la Universidad de Concepción (privada).

- La Universidad Tecnológica Metropolitana (UTEM) ha recibido el $40 \%$ de lo aportado, por alumno, a la PUC.

- El aporte estatal ha favorecido más, en algunos años, a la Universidad Católica del Norte (privada) que a la PUC (privada); y en otros años, a la inversa, lo que acerca los promedios.

- Los aportes fiscales han favorecido siempre a la Universidad Católica del Norte, por sobre la Universidad de Antofagasta (estatal).

Cabe, entonces, subrayar:

En democracia, el financiamiento estatal a las Universidades del Consejo de Rectores ha permanecido por debajo del crecimiento del Producto Interno Bruto (P.I.B.)

Los gobiernos han dado más dinero por alumno al año a las universidades privadas que a las estatales; y entre el aporte a la Universidad de Chile y las restantes 15 universidades del Estado hay diferencias muy grandes; también las hay entre aquellas 15 entidades estatales.

En consecuencia, resulta justificado lo que afirma la Federación de Asociaciones de Académicos de universidades estatales: la educación pública es una función del Estado, cumplida por nuestras casas de estudio, en conformidad con los intereses de la sociedad; agregando que las cifras muestran que en la última década, el Estado entregó anualmente cerca de 5.000 millones más al sub-sistema de universidades privadas, que lo aportado a sus universidades. Las casas de estudio estatales deben, así, con inferioridad de recursos, autofinanciar sobre el $75 \%$ de sus presupuestos, atendiendo incluso necesidades de alimentación, salud, etc. de miles de jóvenes con ingresos insuficientes.

...Las universidades estatales desarrollan (en conjunto) los volúmenes mayores de investigación científica y humanística, de perfeccionamiento académico, de creación artística y extensión del saber y del arte a la sociedad. Sostienen el concepto de formación universitaria, más allá de la sola preparación de profesionales. ${ }^{2}$

La base histórica de la distribución del AFD es racionalmente insostenible. ¿qué impide, entonces, un análisis razonado en el Consejo de Rectores y la disposición de los Poderes Públicos a modificarlo, escuchando a las comunidades universitarias?.

\footnotetext{
${ }^{2}$ FAUECH, Declaración de Iquique, $1^{\circ}$ de julio del 2000.
} 
El AFI es una modalidad de aporte que promueve directamente la inequidad de oportunidades. Los hogares con ingresos suficientes para enviar sus hijos a los colegios privados y usar del entrenamiento para la Prueba de Aptitud Académica (PAA) que ofrece el mercado, concentran gran parte del dinero fiscal con que se premia a los 27.500 mayores puntajes en dicha prueba. Luego, los montos mayores del AFI se concentran en pocas universidades. Así, los aproximadamente 40 millones de dólares del AFI dan un promedio de 60 dólares por alumno. Pero, una universidad estatal como la USACH (que ocupa el tercer lugar en la recepción de los puntajes altos) promedia 125 dólares por alumno. En otras universidades, la cifra es mucho menor.

La USACH percibe un aporte fiscal (AFD más AFI) de 745 dólares por alumno, pero el gasto per cápita bordea los 3.000 dólares. Esa fuente de financiamiento, ha impulsado el alza de aranceles en porcentajes varias veces superior al IPC y, en consecuencia, el retroceso de la equidad de oportunidades. Recuérdese que las asociaciones de académicos estatales han demandado la eliminación del AFI y la distribución de esos fondos con criterios de equidad.

Los llamados Fondos Concursables estructuran la competencia inter-universidades, desconociendo las condiciones de recursos materiales y académicos que las diversas entidades han heredado del pasado reciente: las políticas destructoras, bajo el régimen dictatorial, para con la mayoría de las estatales y el trato privilegiado para algunas entidades tradicionales privadas. En este ámbito intervienen también las universidades privadas no tradicionales que, en general, no consideran entre sus objetivos el aporte a la equidad de oportunidades.

Para finalizar, volvamos al concepto de Universidad Pública que debiéramos construir intelectual y socialmente, como parte indescartable del paradigma de sociedad democrática.

Los procesos históricos que explican cómo el Estado asignó reconocimiento y autonomía en las tareas académicas a las universidades generadas por sectores privados; o bien, las consideraciones acerca de la conveniencia o necesidad de que entidades privadas de educación superior reciban aportes estatales en igualdad de condiciones (en principio) con las universidades del propio Estado, no deben oscurecer la significación del concepto. La educación pública se desarrolló históricamente como palanca de la construcción de la Nación. Esto es, como una función preferente e irrenunciable del Estado que garantiza jurídica-políticamente la igualdad de oportunidades para el acceso a ese bien, sin distinción de índole alguna que no esté referida a los talentos específicos requeridos. Es por ello que la función pública fue identificada con las dos universidades estatales existentes hasta la dictadura. Éstas garantizaban una vida académica enteramente secularizada y laica. Es decir, es en las universidades del Estado donde -ayer y hoy- resulta inaceptable que se privilegie determinada concepción religiosa, intelectual o ideológica. Ellas, actuando en representación de la Nación, deben asegurar el pluralismo más efectivo, la equidad de oportunidades, la libertad de opinión, de investigación y creación.

Esa piedra angular de la modernidad -el Estado secular y laico- hace posible que la educación como función pública sea un bien de la democracia. El saber superior se ofrece a toda la sociedad y no responde a visiones o intereses de una parte de ella, por legítimos que ellos sean.

¿Puede el Estado delegar esa función pública a las iniciativas que se gesten desde la sociedad civil?. Creemos que ello debiera ser posible. La primera condición es, por 
cierto, el pluralismo. Esto es, la ausencia de compromisos institucionales - no individuales- con posturas filosóficas, espirituales o políticas de cualquier signo, que resultan válidas para una parte de la sociedad.

Hoy, en Chile, en cualquier universidad no se puede investigar o exponer cualquier objeto científico o intelectual, si enfrentamos, por ejemplo, ámbitos como la contracepción y el embrión o temas filosóficos, jurídicos, históricos.

Nos parece, igualmente, que la función pública exige de cualquier universidad que aspire a ejercerla, una praxis a favor de la equidad social. Requiere, también, la vigencia de principios democráticos en su vida interna; es incompatible con la identificación entre la propiedad o el control empresarial privados de una universidad, con las estructuras de su gobierno.

Creemos, en consecuencia, que las políticas de Estado deben clarificar el concepto de Misión Pública asignable sólo a entidades que se dispongan a contribuir al mejoramiento de la calidad junto a la equidad de oportunidades. Actualmente, sólo las universidades del Estado cumplen esa misión. (la cual no es sinónimo de capacidad de respuesta -sobre la base de intereses privados- ante demandas de los mercados, puesto que en tal caso la función pública se hace ininteligible, al punto de que habría que reconocérsela a los supermercados).

Estimamos que la cooperación entre universidades dispuestas a jugar el rol público debiera sustituir la competencia vigente, orientada a capturar rentabilidades de mercado. Nos preguntamos, volviendo al inicio de este texto: ¿por qué, entonces, una alianza excluyente entre dos universidades?. La presencia del Presidente de la República en dicho convenio, ¿es señal de una política definida?. Si fuese así, insistimos: ¿cuál es el concepto de Universidad Pública?. Y, ¿qué se espera del desarrollo de las otras universidades, a las cuales no se les considera para forma alguna de cooperación, ni se les indica objetivos ni medios para avanzar en su complejidad, en calidad con equidad?. 